\title{
Book Review: \\ Cyberpsychology - An Introduction to Human-Computer Interaction
}

\author{
Ulas llic \\ Anadolu University, Turkey
}

\begin{abstract}
Contemporary developments in technology have changed our daily practices and located information and communication technologies in the center of our daily lives. Borders between the computer and human are somewhat blurred due to constant technological changes, which are hard to keep up with. Yet, interacting with computers is unavoidable for the $21^{\text {st }}$-century individuals. The term human-computer interaction $(\mathrm{HCl})$ is coined to address these conditions. Interacting with computers helps people in several ways, but also affects individuals' psychological states and behaviors. In this regard, new psychology of the modern age -i.e., cyberpsychology- becomes more important. Thus, it is crucial to understand the psychology of the $\mathrm{HCl}$ in such a technology centered world so that current perspectives and approaches regarding human performance can be improved better. Cyberpsychology can help to solve problems related to $\mathrm{HCl}$ and assist humans to develop their well-beings in the future.
\end{abstract}

The book titled Cyberpsychology: An Introduction to Human-Computer Interaction is authored by Kent L. Norman and published in 2008 by Cambridge University Press, a highly prestigious publisher which has numerous publications across 100 countries. The book consists of 434 pages $(+x)$ and shelters four parts each divided into four chapters. Each chapter begins with one or more intriguing scenarios and an overview of the chapter, which prepares the audience for further contents. Figures and illustrations are presented close to and in concordance with the related content, which ensures a high level of reader-friendliness. The author uses thought-provoking examples related to $\mathrm{HCl}$. In the first parts' chapters, the author refers to forthcoming chapters for further exploration. Similarly, he refers to previous chapters in subsequent parts to address the fundamentals and prerequisites of the discussed issue. At the end of each chapter, at least two suggested exercises are presented to further thinking about real-life problems. On the other hand, further readings regarding the current topic could have been presented for thorough reading from first-hand sources.

The author, Kent L. Norman, is a cognitive psychologist and associate professor at the University of Maryland. His lists his research interests as cognitive psychology, humancomputer interaction, the design of electronic educational environments, and the psychology of video games. He is also the developer of HyperCourseware ${ }^{\mathrm{TM}}$ and a founding member of the Human-Computer Interaction Laboratory in the University of Maryland. The book constitutes the basics of his course with the same title in the University of Maryland. He maintains that materials, notes, and empirical studies of the course entitled "Psychology in the age of computers" helped him write the book. The writing process began in 1984 and took 20 years. In a review of the book, Castleman (2010) considers the aim of the book as an $\mathrm{HCl}$ text, but regards it somewhat elementary in terms of the current psychology and computer science endeavors. 
The book begins with an appealing preface where the author briefly describes the history, contents, and potential readers of the book, which is presented as an introduction to the psychology of $\mathrm{HCl}$. The author further points out that there are no prerequisites to read this book for the target audience. The preface continues with the aim of the book, which is mentioned as covering a wide range of topics in $\mathrm{HCl}$ rather than probing deeply into a few relevant topics. $\mathrm{HCl}$ is discussed through the lens of psychology instead of computer science in the book. Thus, the book's focus is centered on human issues before computer issues. At the end of the preface, the author acknowledges those who contributed to the book.

Chapter 1 begins with the definition of cyberpsychology which is the intersection of human and computer activity. Then, history of psychology and computers related to each other are presented. It is maintained that, before looking for the future of human-computer interface, understanding the past is quite useful. At the end, the author emphasizes that understanding human behavior is a key to realize the importance of human-computer interface. At the end of the chapter, the author introduces the organization of the book where he briefly describes the contents of the subsequent parts and chapters.

Chapter 2 discusses the systems of human and computer through a cognitive science perspective. Human nervous system, logical system and hardware components of computers are introduced. The chapter ends through addressing the similarities and differences of human and computer systems.

The author begins Chapter 3 with three perspectives of human computer interface. He further describes the input/output flow, and provides examples regarding the human computer interface. The chapter continues with mental models, user-task interaction models, and general models and theories on human behavior that motivates $\mathrm{HCl}$. By doing so, the author helps the readers to grasp $\mathrm{HCl}$ processes. The author also points out that only fundamentals of the $\mathrm{HCl}$ are presented in the chapter.

Chapter 4 helps the readers to identify the research methods, which are needed to understand the $\mathrm{HCl}$ studies mentioned in the book. The chapter begins with the steps of scientific methods related to $\mathrm{HCl}$. Empirical studies and laboratory experiments are presented as well. The chapter further discusses the threats in $\mathrm{HCl}$. Finally, the author briefly describes the usability testing and ethical issues in $\mathrm{HCl}$ research.

Chapter $\mathbf{5}$ describes the sensory-motor interfaces related to $\mathrm{HCl}$. Throughout the chapter, it is emphasized that sensation and motor movements are key issues for human computer interface designers to avoid potential problems. The author begins with the discussion of the senses like vision, auditory and touch. Kinesthetic and proprioceptive senses are also introduced. The chapter continues with the motor movements where input devices related to fine-motor movements are presented. At the end, stimulus-response compatibility is discussed briefly.

Chapter 6 addresses the learning and memory issues related to human and the computer. The chapter begins with the discussion of learning and forgetting curves. Then, memory types (i.e., sensory memory, short term memory and long-term memory) are presented. By doing so, the author helps readers to understand recognition, recall and retrieval processes in $\mathrm{HCl}$. Organization of the long-term memory and fundamental differences of learning and memory processes in human and computer are also discussed. The chapter ends with addressing the importance of external memory which will be explored further in Chapter 14. 
Chapter 7 focuses on thinking and problem solving issues while using computers. At the beginning, the author describes the fundamentals of thinking and problem solving. The chapter continues with problem types and problem solving through association, restructuring and processing. Then, strategies for problem solving and information search related to computers are presented. Finally, the author addresses the importance of the combination of human creativity and computer processes for problem solving.

Chapter 8 discusses the use of natural and programming languages. The chapter begins with the description of natural language from the perspectives of psycholinguistics. Psychological aspects of programming languages are considered as well. The chapter ends through addressing the difficulties and limitations of natural language interaction in human-computer interface.

Chapter 9 examines the individual differences from the perspective of $\mathrm{HCl}$. The author begins with the discussion of the factors of differences related to cognitive factors and abilities. In addition, how the demographic information variables (e.g., age, gender, experience, and socioeconomic statues) can lead to differences in $\mathrm{HCl}$ are discussed along with potential solutions. The chapter continues with the assessment of individual differences. Finally, the author points out that it will be easier to assess a person's cognitive styles and abilities with the help of interactive data in future.

Chapter 10 delves with motivation, emotion, and attention issues regarding the humancomputer interface. The chapter begins with the description of the motivation, which is a driving force behind human behaviors. Numerous theories about motivation, emotion and feelings are used to understand these issues related to $\mathrm{HCl}$. In the following parts, sensitiveness of computers to human needs and emotions are discussed. Finally, the author addresses that although computers can't represent the true emotions, they can still be useful for user attention and motivation.

In chapters 1 through 10, interaction between a computer and a human is considered. In Chapter 11, the author changes his perspective to examine the interaction between two or more humans and the system. The chapter begins with an examination of social interaction and cyberspace. Then, he describes the impression formation and management in cyberspace related to real-life examples. In the following parts of the chapter, social pressure, anonymity, attitude, altruism and helping behavior issues are presented. Group processes such as group dynamics, structure and networks are discussed at the end of the chapter as well.

Chapter 12 discusses the psychological disorders caused by the technology usage which is followed by the introduction of the term "cybertherapies". The chapter begins with psychological problems in cyberspaces. The description of disorders and their involvement with $\mathrm{HCl}$ are introduced followed by the discussion of cyberpathologies (e.g., internet addiction, computer rage, cybersex, online gaming). Finally, the author addresses the ways to cope with disorders in the cyberspace such as computer mediated therapy and counseling.

Chapter 13 focuses on the issue of automation and the development of artificial intelligence (i.e., A.I.). At the beginning, the author describes the automation process and discusses things to automate. He further emphasizes that individuals should stay in the automation loop which is addressed through the term "human complacence". The definition, historical developments, and advantages and disadvantages of the A.I. are discussed in the chapter as well. The author 
concludes the chapter through pointing out that it is too early to understand the effects of A.I. on individuals.

Chapter 14 describes the implications of assistive and augmentive technologies. The chapter begins with the terms assistive technology, universal access and the idea of equal access. Then, psychological implications of new technologies that enhance human abilities are introduced. The chapter continues with describing visual, auditory and cognitive impairments along with potential solutions to these impairments. The term augmentive technologies is discussed as well. The chapter ends through addressing the potentials of assistive and augmentive technologies to ameliorate human experience.

Chapter 15 discusses the psychological issues in video games and educational value of computers in teaching. At the beginning, the author addresses the video games along with their taxonomy and psychology. The chapter further discusses the importance of educational software and multimedia materials in training and education. The author ends the chapter through pointing out the concerns about the virtual courses and degrees through discussing their low educational quality.

Chapter 16 focuses on the future of psychology, cyberpsychology, and $\mathrm{HCl}$. The author begins the chapter with the terms social computing and disappearing computers, which are blurring the borders between humans and machines. At the end of the chapter, the author discusses the implications of the cyberpsychology and points out that cyberpsychology will help humans to build a better world through new technology.

To conclude, the author, Kent L. Norman tries to make a modest contribution to the $\mathrm{HCl}$ field through embracing a psychology perspective. While talking about the $\mathrm{HCl}$, it is not easy to predict the future. However, through understanding the psychology of $\mathrm{HCl}$, it can be easier to use the contemporary technology more effectively, and solve the current and potential human performance problems better. Even though the book can be regarded as elementary and imperfect for a scholar who is familiar with the contemporary $\mathrm{HCl}$ research, it can be considered as a reader-friendly and intriguing starting point for undergraduate students of instructional technology and psychology, who may want to probe further into $\mathrm{HCl}$. In addition, the text can contribute to computer interface designers and people studying in computer science as well. The book can also be used as a useful resource for anybody interested in $\mathrm{HCl}$ to understand the new psychology of the digital age: Cyberpsychology.

\section{References}

Castleman, W. A. (2010). Psychology in a technological age is the study of human-computer interaction [Review of the book Cyberpsychology: An introduction to human-computer interaction]. New York, NY: Cambridge University Press.

Correspondence: Ulas Ilic, Doctoral Student, Graduate School of Educational Sciences, Anadolu University, Yunus Emre Campus, Eskisehir, Turkey 